\title{
Influence of Environmental Factors on Injury Severity Using Ordered Logit Regression Model in Limpopo Province, South Africa
}

\author{
Peter M. Mphekgwana (iD \\ Research Administration and Development, University of Limpopo, Polokwane, South Africa \\ Correspondence should be addressed to Peter M. Mphekgwana; peter.mphekgwana@ul.ac.za
}

Received 7 August 2021; Revised 19 January 2022; Accepted 26 January 2022; Published 21 February 2022

Academic Editor: Chunrong Jia

Copyright (c) 2022 Peter M. Mphekgwana. This is an open access article distributed under the Creative Commons Attribution License, which permits unrestricted use, distribution, and reproduction in any medium, provided the original work is properly cited.

\begin{abstract}
Globally, road traffic accidents are a major cause of death and severe injuries. It is estimated that the number of deaths on the world's roads at 1.5 million per annum puts road traffic injuries as the eighth leading cause of death globally. Understanding the influence of environmental factors on deaths and severe injuries will help in policy-making and the development of strategies in Limpopo Province. We, therefore, aim to study environmental factors that influence road deaths and severe injuries and to identify whether their impact on injury severity levels varies. The study was based on secondary data on road traffic accidents obtained from the Department of Roads and Transport in Limpopo Province. The data comprised 18029 road traffic accidents for the period January 2009-December 2015. The study found that weekends (Saturdays and Sundays) had the highest number of accidents when compared to weekdays. The proportion of observations in each severity level was not constant across explanatory variables. The generalized ordered logit regression (GOLR) models seemed to be an effective predicting model that can be adapted to determine the influence of environmental factors on injury severity compared to the ordered logit regression (OLR) model. The results of the GOLR model suggest that environmental factors such as slippery road conditions, rainy weather, and spring season lower the likelihood of severe crash occurrence. On the other hand, poor or defective road surface, time interval (6 a.m. to 11 p.m.), and provincial roads have a higher likelihood of severe crash occurrence. To decrease the severity of injuries in the province, provincial roadways must be maintained regularly.
\end{abstract}

\section{Introduction}

Globally, Road Traffic Accidents (RTAs) are a major cause of death and severe injuries. In its 2018 report, the World Health Organization (WHO) estimated the number of deaths on the world's roads at 1.5 million per annum and put road traffic injuries as the eighth leading cause of death globally [1]. It also stated that between 20 and 50 million more people suffer nonfatal injuries, with many incurring a disability as a result of their injuries. The social and economic costs of deaths and injuries due to RTAs are over US\$100 billion annually [2]. Also, RTAs were seen to be some of the main leading causes of death among people under the age of 40 years [3].
Regionally, Africa, with only $2 \%$ of the world's vehicles, is the least motorized region of the world but contributes $16 \%$ of the global traffic deaths with Nigeria and South Africa contributing a significant proportion of these deaths [1]. Overall, young Africans aged between 15 and 29 years are most vulnerable to these RTAs [1]. The burden of Road Traffic Deaths (RTDs) is reported to be on the rise in developing countries such as South Africa despite increased efforts to address these traffic accidents. The 2016 report of the Road Traffic Management Corporation states that the number of RTDs increased by $10 \%$ between the years 2014 and 2015 [4]. This annual road carnage costs the South African economy approximately R43 billion, of which $60 \%$ is due to damage to vehicles and other properties $[5,6]$. 
In 2015, 10613 fatal accidents occurred between January and December 2015 and resulted in 12944 fatalities in the country with a rate severity of 1.2 [7]. Previous studies in this field have identified various factors that are associated with RTAs and RTDs. These include, among others, sociodemographics such as the age of the driver, gender, speeding, not wearing a seat belt, vision deficiency that is corrected with the eyeglass, dark but lighted conditions (07:30 pm to 05:30 am), rainy seasons, drivers under the influence of drugs or alcohol, drivers exhibiting aggressive driving behaviour, and negative road engineering factors as well as quality of pavement [8-13].

To the best of our knowledge, information on the influence of environmental factors on death and severity of injuries on Limpopo Province roadway highways is still limited. It is, therefore, in this context that the present study aimed to contribute to the literature on environmental risk factors associated with deaths and severe injuries and to identify whether their impact on injury severity levels varies. In doing so, we use the ordered logit regression model (OLR) and will consider some extensions with the ultimate goal of producing a robust model for modeling death and severity injuries in the province. Researching on the impact of environmental factors on death and severe injuries in Limpopo Province of South Africa is of particular relevance to government and public health in the development of strategies to reduce road deaths and severe injuries.

\section{Literature Review}

A previous study conducted in South Africa by Vogel and Bester classified risk factors influencing road traffic crashes as human, vehicle, and road and environment factors [14]. Human factors included negligence, excess speed, dangerous overtaking, pedestrians in the road, and inconsiderate driving behaviour. Vehicle factors were mostly about faulty brakes and tyres. Road and environmental factors included rush-hour traffic and inadequate facilities for pedestrians. The study found that human factors accounted for $75 \%$ of the accidents, followed by environmental (15\%) and vehicle factors (10\%) [14].

Various studies have shown that environmental factors were significantly related to risk road fatalities. A study conducted by Jung et al. in southeastern Wisconsin assessed the effects of rainfall on the severity of single-vehicle accidents, taking into account weather-related factors such as estimated rainfall intensity for 15 minutes before accident occurrence, water film depth, temperature, wind speed/direction, stopping sight distance, and car-following distance at the time of the crash [15]. The study found that rainfall intensity, wind speed, and horizontal or vertical curves were all linked to an increased likelihood of accident severity in rainy weather. More accidents commonly occurred inroads with two-way traffic as opposed to single-way roads [16]. Furthermore, the risk decreases with the width of the road. Moreover, studies have found a link between road accident frequency and risk factors such as road segment length, width, number of ramps and bridges, horizontal and vertical curves, and shoulder-width [17].
A high proportion of road accidents and deaths occur during the night between 6 p.m. and 6 a.m. and during peak times between 12 p.m. and 6 p.m. [12]. Some accidents are caused by a lack of street lights, particularly during nighttime driving on undivided 2-lane or 2-way rural highways [18]. This could lead to difficulty in distinguishing the lane separation which might cause an accident. The probability of fatality is estimated to rise when dull lighting conditions are present [13]. Multivehicle accidents commonly occur in offpeak hours during the daytime [8].

Modeling of traffic accident injury severity is complex and has received more attention in recent years [19]. Several statistical models have been used to estimate the severity of traffic injuries. A study done in New Mexico from 2010 to 2011 used multinomial logit regression models to investigate the characteristics that differentiate teenage and adult drivers in intersection-related accidents [20]. However, it should be emphasized that the injury severity response variable has the nature of the scale that underlies the items (no injury, minor injury, severe injury, fatality) which renders the multinomial logit regression model unsuitable for analyzing injury severity. A recent study conducted in China investigating the statistical distribution characteristics such as types of environmental properties and road properties deployed an ordered logit regression (OLR) model to account for the unobserved heterogeneity across observations and also cater for choices that have an inherent order to them [21]. OLR models are among the most common ordinal regression techniques; however, they often have serious shortcomings [22]. These approaches frequently violate the proportionate odds/parallel lines assumptions. Model misspecification can cause issues that are worse than the ones that these strategies were designed to address. One of the alternatives to address violated proportional assumption is to use generalized ordered logit regression (GOLR) models as they may emphasize a proportion of observations in each level of the response if not consistent across each level of the explanatory variable [22].

\section{Materials and Methods}

3.1. Study Setting, Population, and Data Collection. This study is based on secondary data on RTAs obtained from the Limpopo Provincial Department of Roads and Transport. Limpopo is the northernmost province of South Africa with an estimated population of 5 million. It comprises five districts, namely, Capricorn, Mopani, Sekhukhune, Vhembe, and Waterberg. The data comprised 18029 RTAs over the period 2009 January-December 2015. A single record for each accident was created along with a set of variables indicating severity, time of the accident, locations, and the cause as shown in Table 1.

3.2. Statistical Analysis. All data analyses were performed using SPSS version 26.0 (IBM SPSS Statistics) (IBM, Chicago, USA) and $R$ software. Baseline characteristics of the RTAs were expressed as frequencies and percentages, and the Mantel-Haenszel extension test was used to test for linear trends in the injury severity level. 
TABle 1: Data categories and variables used in the study.

\begin{tabular}{|c|c|c|}
\hline Variables & Description & Values \\
\hline Severity level & Injury severity & $\begin{aligned} 1=\text { property damage } ; & =\text { minor injury; } 3=\text { serious injury; } 4=\text { deaths } \\
1 & =\text { Monday } 2=\text { Tuesday }\end{aligned}$ \\
\hline Day of week & One of the seven days in a week & $\begin{array}{c}3=\text { Wednesday } 4=\text { Thursday } \\
5=\text { Friday } 6=\text { Saturday } \\
7=\text { Sunday }\end{array}$ \\
\hline District & Municip & $1=$ Capricorn; $2=$ Vhembe; $3=$ Mopani; $4=$ Greater Sekhukhune; $5=$ Waterberg \\
\hline & & $1=$ autumn; $2=$ spring; $3=$ summer; $4=$ winter \\
\hline Road type & Categorized road type & $1=$ regional $; 2=$ district $; 3=$ national $; 4=$ others \\
\hline Time & Categorized time intervals & $1=00: 00-05: 59 ; 2=00: 06-13: 59 ; 3=14: 00-23: 59$ \\
\hline
\end{tabular}

3.2.1. Ordered Logit Regression Model (OLR). The ordered logit regression model (OLR) was applied to determine the relationship and determinants of death and severe injuries. Suppose $Y$ denotes the ordinal outcome with $j$ categories and $\mu$ is the corresponding conditional mean. The odds ratio of being less than or equal to particular $j$ categories is given as

$$
\frac{P_{r}\left[Y_{i} \leq j \mid X\right]}{P_{r}\left[Y_{i}>j \mid X\right]}=\frac{P_{r}\left[Y_{i} \leq j \mid X\right]}{P_{r}\left(1-P_{r}\left[Y_{i} \leq j \mid X\right]\right)}, \quad j=1,2,3,4 .
$$

Considering ordered logit function

$$
\begin{aligned}
\operatorname{logit}\left(P_{r}\left[Y_{i} \leq j \mid X\right]\right) & =\operatorname{In}\left(\frac{P_{r}\left[Y_{i} \leq j \mid X\right]}{P_{r}\left[Y_{i}>j \mid X\right]}\right) \\
& =\operatorname{In}\left(\frac{P_{r}\left[Y_{i} \leq j \mid X\right]}{P_{r}\left(1-P_{r}\left[Y_{i} \leq j \mid X\right]\right)}\right), \quad j=1,2,3,4 .
\end{aligned}
$$

The OLR is defined as

$$
\operatorname{logit}\left(P_{r}\left[Y_{i}>j\right]\right)=-a_{j}+\beta x_{i}^{\prime},\left\{\begin{array}{l}
j=1,2,3,4, \\
i=1, \ldots, n,
\end{array}\right.
$$

where $a$ is the slope of the model, $\beta$ is the coefficient of the model, $i$ is the explanatory variable, and $j$ is the severity level (property damage, minor injuries, serious injuries, and death). Then $\beta$ is assumed to be the same for all the explanatory variables.

3.2.2. Generalized Ordered Logit Regression (GOLR). The generalized ordered logit regression model (GOLR) was applied to determine the relationship and determinants of death and severe injuries. Suppose $Y$ denotes the ordinal outcome with $j$ categories and $\mu$ is the corresponding conditional mean. The odds ratio of being less than or equal to particular $j$ categories is given as

$$
\frac{P_{r}\left[Y_{i} \leq j \mid X\right]}{P_{r}\left[Y_{i} \leq j \mid X\right]}=\frac{P_{r}\left[Y_{i} \leq j \mid X\right]}{P_{r}\left(1-P_{r}\left[Y_{i} \leq j \mid X\right]\right)}, \quad j=1,2,3 .
$$

Considering ordered logit function

$$
\begin{aligned}
\log i t\left(P_{r}\left[Y_{i} \leq j \mid X\right]\right) & =\operatorname{In}\left(\frac{P_{r}\left[Y_{i} \leq j \mid X\right]}{P_{r}\left[Y_{i}>j \mid X\right]}\right) \\
& =\operatorname{In}\left(\frac{P_{r}\left[Y_{i} \leq j \mid X\right]}{P_{r}\left(1-P_{r}\left[Y_{i} \leq j \mid X\right]\right)}\right), \quad j=1,2,3,4 .
\end{aligned}
$$

The GOLR regression model is defined as

$$
\operatorname{logit}\left(P_{r}\left[Y_{i}>j\right]\right)=-a_{j}+\sum_{1}^{n} \beta_{i} x_{i},\left\{\begin{array}{l}
j=1,2,3,4, \\
i=1, \ldots, n,
\end{array}\right.
$$

where $a$ is the slope of the model, $\beta$ is the coefficient of the model, $i$ is the explanatory variable, and $j$ is the severity level (property damage, minor injuries, serious injuries, and deaths). Then $\beta$ is not the same for all the explanatory variables.

3.2.3. K-Means Clustering. K-means clustering is a popular method for cluster analysis in data mining. It partitions $n$ observations into $\mathrm{K}$ clusters in which each observation belongs to the cluster with the nearest mean. Given a set of observations $\left(x_{1}, x_{2}, \ldots, x_{n}\right)$, where each observation is a $d$-dimensional real vector, $\mathrm{K}$ means clustering aims to partition the observation into $K(\leq n)$ sets to minimize the within-cluster sum of squares.

3.2.4. Brant Test. The Brant test developed by Rollin Brant in 1990 was used in the study to assess whether the observed deviations from the OLR model are larger than what could be attributed to chance alone [23].

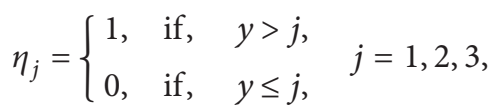

with success probability, $\pi_{j}=P_{r}\left[\eta_{j}=1\right]=1-\gamma_{j}$ satisfy. $\operatorname{logit}\left(\pi_{j}\right)=-a_{j}+\beta x_{i}^{\prime}$.

\subsection{Wald-Type Goodness-of-Fit Statistic.}

$$
\chi^{2}=(D \widehat{\beta})^{\prime}\left[D \widehat{V} \widehat{\beta} D^{\prime}\right]^{-1}(D \widehat{\beta}) \sim \chi_{(k-2) p}^{2},
$$

where 


$$
D=\left[\begin{array}{cccc}
I & -I & 0 \\
I & 0 & -I \\
\cdots & \ldots & \cdots \\
I & & 0 & 0 \\
& \cdots & 0 & \\
& \cdots & 0 & \\
& \cdots & \cdots & \\
& \cdots & -I &
\end{array}\right]
$$

If $\chi^{2}$ is found to be significant, individual differences $\widehat{\beta}_{j}-\widehat{\beta}_{l}$ may be considered concerning their approximate standard errors to elucidate the nature of the lack of fit.

3.4. Ethical Considerations. Permission to conduct the study was obtained from the University of Limpopo Turfloop Research and Ethics Committee (TREC/21/2019[NEI]) and the Department of Roads and Transport in Limpopo Province.

\section{Results}

Figure 1 illustrates a breakdown of RTAs by day of the week during a seven-year period in Limpopo Province of South Africa. The graph shows that weekends (Saturdays and Sundays) had the largest number of RTAs when compared to weekdays. The proportion of property damage, minor injuries, serious injuries, and mortality caused by an animal in a roadway was $82 \%, 83 \%, 79 \%$, and $65 \%$, respectively (shown in Table 2). The majority of fatal crashes occurred between 2 : 00 and $11: 00$ p.m., with $75.63 \%$ of property damage, $74.60 \%$ of minor injuries, $73.42 \%$ of serious injuries, and $55.41 \%$ of fatalities within those hours, shown in Table 2 . The majority of traffic fatalities and injuries in this province happened on regional roads in Capricorn District. There was a significant linear trend observed for all the variables.

Table 3 shows the results of the ordered logit regression for associations between severity and related environmental factors in Limpopo Province, South Africa. Using a significance level of 0.05 , the model findings show an association between environmental conditions, hour interval, road type, and region with the severity of injuries. Driving on roads with potholes, the odds of being more likely severe is 2.59 times higher than driving on animal-infested roadway, holding constant all other variables. The odds of being less severe is 0.67 lower than driving between 2:00 pm and 11:00 pm as compared to driving between 12:00 pm and 5:00 am. Driving on a provincial road, the odds are 0.30 less severe as compared to driving on districts roads holding all other variables constant. Driving in Mopani, Sekhukhune, Vhembe, and Waterberg districts is more likely severe than driving in Capricorn district.

The OLR model is based on the assumption that each independent variable has the same influence at each cumulative split of the ordered dependent variable. To check the model's adequacy and proportional odds assumption, the Hosmer-Lemeshow goodness-of-fit and Brant tests were performed. The goodness-of-fit test revealed that the model was well-fitting (likelihood ratio statistic $=5.88$, degree of freedom $=9, P$ value $=0.7514)$. Brant's conclusion shows that the data did not meet the parallel lines assumption (chisquare $=74.04$, degree of freedom $=38, P$ value $=0.0004)$, indicating that fitting the OLR model to the data was unsuccessful (shown in Table 4). As a result, in order to accommodate the proportionality constraint, we explore fitting the GOLR model. The model-fitting results are shown in Table 5.

Table 5 shows the results of the GOLR model for associations between deaths and severe injuries and related environmental factors in Limpopo Province, South Africa. Using a significance level of 0.05 , the model findings show an association between environmental conditions, hour interval, season, road type, and region with severity. Driving on a slippery road is less likely to result in death and severe injuries than driving on animal inroads, suggesting that vehicle crashes are less likely to result in death and severe injuries when driving on a slippery road than when driving on the animal inroads. The odds of a car crash due to a stationary or parked vehicle on the road are 0.31 and 0.41 , suggesting that vehicle crashes are less likely to result in minor injuries and death, respectively, compared to the odds of vehicle crashes due to animals on the roads. Vehicle crashes on poor or defective road surfaces were more likely to result in death and serious injuries. Driving in rainy weather is less likely to result in death and serious injuries than vehicle crashes due to animals on the roads.

$\mathrm{K}$-means clustering was used as a clustering method for splitting the time of day into a set of $k$ groups. We have grouped the time of day into 3 groups (00:00 a.m.-05:00 a.m., 06:00 a.m.-01:00 p.m., and 02:00 p.m.-11:00 p.m.) using the unsupervised $\mathrm{k}$-means algorithm. The study results showed that the odds of a vehicle crash during 06-13 and 14-23 hours are 1.52 and 2.78, respectively, suggesting that vehicle crashes are more likely to result in deaths and severe injuries compared to the odds of a vehicle crash during 00-05 hours. Vehicle crashes during spring are less likely to result in deaths and severe injuries than driving during the autumn season. This suggests that vehicle crashes are less likely to result in deaths and severe injuries when driving in the spring season than during autumn. Vehicle crashes during winter were less likely to result in deaths against nondeaths.

Vehicle crashes on national roads are less likely to result in deaths and serious injuries than on district roads. Driving on provincial roads plays an important role in distinguishing the severity of vehicle crashes (death, minor, and serious injuries) from vehicle crashes that did not result in property damage but do not play a significant role in distinguishing the property damage and injuries from vehicle crashes that resulted in deaths. Regional roads were less likely to result in deaths and serious injuries as compared to district roads. Vehicle crashes in Mopani and Waterberg districts were less likely to result in deaths and injuries than in Capricorn district, suggesting that vehicle crashes are less likely to result in deaths and injuries when driving in Mopani and Waterberg districts than in Capricorn district. Vehicle 


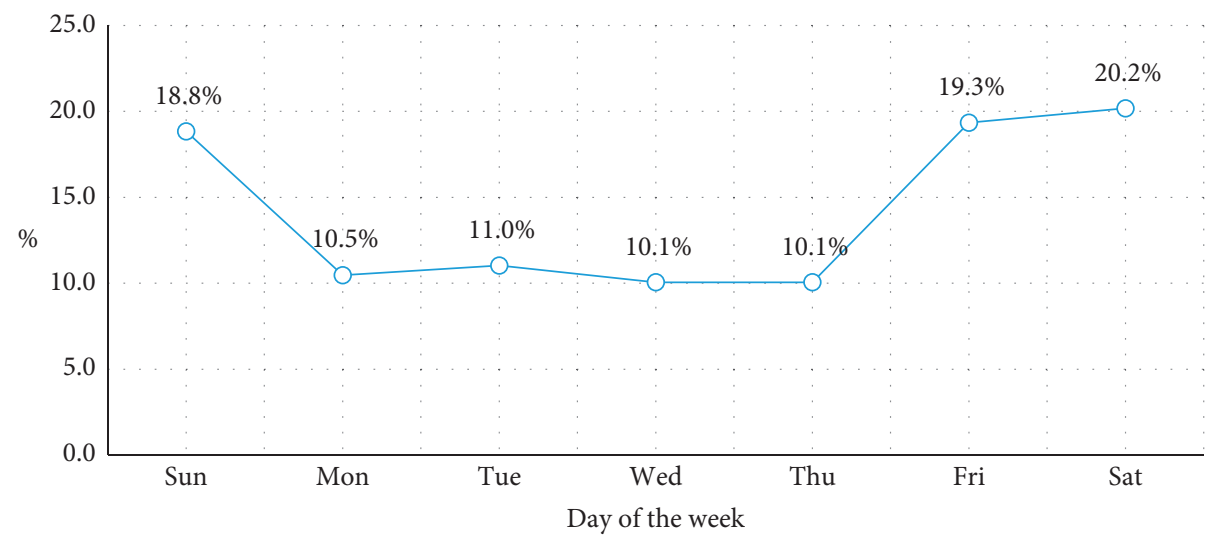

FIgURE 1: Weekly distribution characteristics of road accidents over a seven-year period.

TABLE 2: Frequency analysis of road accidents characteristics by property damage, death, and severe injuries.

\begin{tabular}{|c|c|c|c|c|c|}
\hline Response & Property damage & Minor injury & Serious injury & Deaths & $P$ trend \\
\hline Environmental condition & & & & & $<0.001$ \\
\hline Animal in roadway & $484(81.90 \%)$ & $366(82.99 \%)$ & $249(78.80 \%)$ & $48(64.86 \%)$ & \\
\hline Deposit on road & $8(1.35 \%)$ & $5(1.13 \%)$ & $6(1.90 \%)$ & $4(5.41 \%)$ & \\
\hline Poor or defective road surface & $21(3.55 \%)$ & $18(4.08 \%)$ & $10(3.16)$ & $2(2.70 \%)$ & \\
\hline Potholes & $4(0.68 \%)$ & $9(2.04 \%)$ & $9(2.85 \%)$ & $3(4.05 \%)$ & \\
\hline Rain & $48(8.12 \%)$ & $27(6.12 \%)$ & $23(7.28 \%)$ & $6(8.11 \%)$ & \\
\hline Slippery road & $12(2.03 \%)$ & $12(2.72 \%)$ & $8(2.53 \%)$ & $3(4.05 \%)$ & \\
\hline Stationary or parked vehicle & $14(2.37 \%)$ & $4(0.91 \%)$ & $11(3.48 \%)$ & $8(10.81 \%)$ & \\
\hline Hour interval & & & & & 0.003 \\
\hline 00-05 hours & $65(11.00 \%)$ & $50(11.34 \%)$ & $50(15.82 \%)$ & $16(21.62 \%)$ & \\
\hline 06-13 hours & $79(13.37 \%)$ & $62(14.06 \%)$ & $34(10.76 \%)$ & $17(22.97 \%)$ & \\
\hline 14-23 hours & $447(75.63 \%)$ & $329(74.60 \%)$ & $232(73.42 \%)$ & $41(55.41 \%)$ & \\
\hline Season & & & & & $<0.001$ \\
\hline Autumn & $177(29.95 \%)$ & $138(31.29 \%)$ & $100(31.65 \%)$ & $16(21.62 \%)$ & \\
\hline Spring & $162(27.41 \%)$ & $135(30.61 \%)$ & $83(26.27 \%)$ & $19(25.68 \%)$ & \\
\hline Summer & $114(19.29 \%)$ & $84(19.05 \%)$ & $73(23.10 \%)$ & $17(22.97 \%)$ & \\
\hline Winter & $138(23.35 \%)$ & $84(19.05 \%)$ & $60(18.99 \%)$ & $22(29.73 \%)$ & \\
\hline Road type & & & & & $<0.001$ \\
\hline District & $44(7.45 \%)$ & $41(9.30 \%)$ & $29(9.18 \%)$ & $6(8.11 \%)$ & \\
\hline National & $73(12.35 \%)$ & $53(12.02 \%)$ & $51(16.14 \%)$ & $17(22.97 \%)$ & \\
\hline Others & $79(13.37 \%)$ & $54(12.24 \%)$ & $31(9.81 \%)$ & $11(14.86 \%)$ & \\
\hline Provincial & $14(2.37 \%)$ & $8(1.81 \%)$ & $1(0.32 \%)$ & $1(1.35 \%)$ & \\
\hline Regional & $381(64.47 \%)$ & $285(64.63 \%)$ & $204(64.56 \%)$ & $39(52.70 \%)$ & \\
\hline Regional distribution & & & & & $<0.001$ \\
\hline Capricorn district & $311(52.62 \%)$ & $195(44.22 \%)$ & $125(39.56 \%)$ & $15(20.27 \%)$ & \\
\hline Mopani district & $129(21.83 \%)$ & $127(28.80 \%)$ & $84(26.58 \%)$ & $15(20.27 \%)$ & \\
\hline Sekhukhune district & $23(3.89 \%)$ & $23(5.22 \%)$ & $23(7.28 \%)$ & $14(18.92 \%)$ & \\
\hline Vhembe district & $52(8.80 \%)$ & $31(7.03 \%)$ & $31(9.81 \%)$ & $12(16.22 \%)$ & \\
\hline Waterberg district & $76(12.86 \%)$ & $65(14.74 \%)$ & $53(16.77 \%)$ & $18(24.32 \%)$ & \\
\hline
\end{tabular}

crashes in Waterberg district were less likely to result in deaths against nondeaths as compared to Capricorn district.

\section{Discussion}

A study by Malin et al. found an increase in accident risks for poor road weather conditions such as heavy rain and slippery road conditions $[15,24,25]$. This might be because driving in rainy weather affects the driver's sight, the vehicle's traction, and the risk of an accident increases
$[15,25,26]$. This is similar to the findings of the current study, which discovered that slippery road and rainy weather conditions were associated with deaths and severe injuries. Driving in rainy weather makes it difficult for drivers to maintain control of their vehicles since the road becomes more slippery [23]. Even though the majority of accidents occur due to bad weather [24-26], this study found that rain, slippery road conditions, and a stationary or parked vehicle significantly reduce road injury severity. Previous research came to similar conclusions, indicating that rain, snowy or slippery roads, and congested roadways decreased severity 
TABLE 3: The ordered logit regression for associations between severity and related environmental factors in Limpopo Province, South Africa.

\begin{tabular}{|c|c|c|c|c|}
\hline Variable & Response & Odds $(95 \% \mathrm{CI})$ & $t$-value & $P$ value \\
\hline \multirow{4}{*}{ Intercept } & Property damage & Reference & & \\
\hline & Minor injury & $0.7204(0.2237 ; 1.2170)$ & -1.2938 & 0.1957 \\
\hline & Serious injury & $2.8134(2.3142 ; 3.3126)$ & 4.0612 & $<0.0001^{*}$ \\
\hline & Deaths & $20.547(20.006 ; 21.0876)$ & 10.9534 & $<0.0001^{*}$ \\
\hline \multirow{7}{*}{ Environmental condition } & Animal in roadway & Reference & & \\
\hline & Deposit on road & $1.4450(0.6345 ; 3.2853)$ & 0.8824 & 0.3775 \\
\hline & Poor or defective road surface & $0.8679(0.5089 ; 1.4664)$ & -0.5261 & 0.5987 \\
\hline & Potholes & $2.5884(1.2672 ; 5.3239)$ & 2.6083 & $0.0090^{*}$ \\
\hline & Rain & $0.7898(0.5252 ; 1.1821)$ & -1.1414 & 0.2536 \\
\hline & Slippery road & $1.2668(0.6690 ; 2.3845)$ & 0.7323 & 0.4639 \\
\hline & Stationary or parked vehicle & $1.9667(0.9932 ; 3.8907)$ & 1.9473 & 0.0514 \\
\hline \multirow{3}{*}{ Hour interval } & 00-05 hours & Reference & & \\
\hline & 06-13 hours & $0.6872(0.4635 ; 1.0178)$ & -1.8698 & 0.0615 \\
\hline & 14-23 hours & $0.6737(0.4999 ; 0.9084)$ & -2.5936 & $0.0094^{*}$ \\
\hline \multirow{4}{*}{ Season } & Autumn & Reference & & \\
\hline & Spring & $1.0267(0.7956 ; 1.3250)$ & 0.2029 & 0.8391 \\
\hline & Summer & $1.1466(0.8649 ; 1.5197)$ & 0.9522 & 0.3409 \\
\hline & Winter & $0.9667(0.7311 ; 1.2774)$ & -0.2375 & 0.8122 \\
\hline \multirow{5}{*}{ Road type } & District & Reference & & \\
\hline & National & $1.2356(0.7690 ; 1.9885)$ & 0.8734 & 0.3823 \\
\hline & Others & $0.9559(0.6049 ; 1.5123)$ & -0.1929 & 0.8470 \\
\hline & Provincial & $0.3038(0.1215 ; 0.7226)$ & -2.6386 & $0.0083^{*}$ \\
\hline & Regional & $1.0324(0.7080 ; 1.5099)$ & 0.1655 & 0.8684 \\
\hline \multirow{5}{*}{ Regional distribution } & Capricorn district & Reference & & \\
\hline & Mopani district & $1.5442(1.2080 ; 1.9744)$ & 3.4685 & $<0.0001^{*}$ \\
\hline & Sekhukhune district & $2.9979(1.9280 ; 4.6739)$ & 4.8665 & $<0.0001^{*}$ \\
\hline & Vhembe district & $2.0304(1.3236 ; 3.1152)$ & 3.2472 & $0.0017^{*}$ \\
\hline & Waterberg district & $1.6434(1.2160 ; 2.2208)$ & 3.2356 & $0.0012^{*}$ \\
\hline
\end{tabular}

${ }^{*} P$ value: significant at 0.05 .

$[27,28]$. This might be due to the fact that rainy weather causes reduction in the daily traffic volume and driving speed [29]. Our study findings also revealed that a poor or defective road surface increases the risk of death and serious injuries. Similar to earlier research, it was discovered that poor pavement conditions were linked to proportionally more severe injuries and that very poor pavement conditions were associated with fewer severe crashes [30, 31].

Our study also revealed that the hours of 06 a.m. to 1 p.m. and 2 to 11 p.m. significantly increased the likelihood of serious injuries to death when compared to the hours of 12 p.m. to 5 a.m., which may be attributed to the fact that the majority of individuals are going to and from various workplaces and schools. According to a study conducted by Meng (2017) estimating crash severity on mountainous freeways in Chongqing, accidents occurring between 19 and 24 p.m. were found to be more severe because of the driver's visual response, psychological load, and the road environment. The study also found that the degree of mutual adaptation is more unfavourable to the driver [32]. It was also stated that the likelihood of major traffic accidents is higher in summer and autumn than in the spring and winter. However, similar to the study findings, the likelihood of road severity against property damage decreased in spring compared to autumn, and the chance of death against nondeath decreased in winter season as compared to autumn. Summer was not found to be significantly associated with the severity of injuries.
It was reported in previous studies that minor and serious accidents are more frequent in urban areas, whereas fatal accidents are more likely in rural areas [33, 34]. This study found that national and provincial roads significantly reduce injury severity as compared to district roads. $\mathrm{Na}-$ tional roads are routes connecting major cities; provincial roads connect smaller cities and towns to the national route network; regional roads connect smaller towns to the route network; and district roads are mostly found in the rural areas where they connect market centres to provincial roads. Furthermore, in this study, it was revealed that Sekhukhune and Waterberg districts were less severe compared to Capricorn district. This might be due to the fact that Capricorn is a more developed district, and the capital city is situated in this region. Mopani and Vhembe were found not to be significantly associated with deaths and severe injuries.

The findings further showed that most road accidents in the province occurred during the weekend. This might be due to the increased congestion and traffic volume as a result of weekend travel. Contrary to this finding, Sangkharat et al. found a smaller number of road accidents on weekends compared to weekdays [35]. The disparity in the results might be attributed to weekend activities and traffic flow between these two countries (Thailand and South Africa). There was a significant linear trend for all the variables, suggesting that road accidents due to environmental factors vary according to injury severity. This is similar to findings 
TABle 4: The model goodness of fit using Brant test.

\begin{tabular}{|c|c|c|c|c|}
\hline Variable & Response & Chi-square & Degree of freedom & $P$ value \\
\hline \multirow{6}{*}{ Environmental condition } & Deposit on road & 2.81 & 2 & 0.2448 \\
\hline & Poor or defective road surface & 0.48 & 2 & 0.7853 \\
\hline & Potholes & 0.40 & 2 & 0.8169 \\
\hline & Rain & 1.76 & 2 & 0.4153 \\
\hline & Slippery road & 0.07 & 2 & 0.9633 \\
\hline & Stationary or parked vehicle & 13.82 & 2 & $0.0010^{*}$ \\
\hline \multirow{3}{*}{ Hour interval } & 06-13 hours & 2.87 & 2 & 0.2383 \\
\hline & $14-23$ hours & 3.26 & 2 & 0.1964 \\
\hline & Spring & 2.24 & 2 & 0.3263 \\
\hline \multirow[t]{2}{*}{ Season } & Summer & 1.23 & 2 & 0.5410 \\
\hline & Winter & 7.88 & 2 & $0.0194^{*}$ \\
\hline \multirow{4}{*}{ Road type } & National & 1.35 & 2 & 0.5102 \\
\hline & Others & 3.82 & 2 & 0.1483 \\
\hline & Provincial & 3.66 & 2 & 0.1600 \\
\hline & Regional & 1.05 & 2 & 0.5904 \\
\hline \multirow{4}{*}{ Regional distribution } & Mopani district & 1.03 & 2 & 0.5972 \\
\hline & Sekhukhune district & 9.00 & 2 & $0.0111^{*}$ \\
\hline & Vhembe district & 10.56 & 2 & $0.0051^{*}$ \\
\hline & Waterberg district & 3.74 & 2 & 0.1540 \\
\hline Overall & & 74.04 & 38 & $0.0004^{*}$ \\
\hline
\end{tabular}

$P$ value: significant at 0.05 .

TABLE 5: The generalized ordered logit regression for associations between severity and related environmental factors in Limpopo Province, South Africa.

\begin{tabular}{|c|c|c|c|c|}
\hline Variable & Response & Model 1 & Model 2 & Model 3 \\
\hline \multirow[t]{4}{*}{ Intercept } & Intercept & $23.9693(0.3775)$ & $20.6316(0.5987)$ & $14.4687(0.0090)^{*}$ \\
\hline & Animal in roadway & Reference & & \\
\hline & Deposit on road & $0.3857(0.2536)$ & $0.2575(0.4639)$ & $0.4376(0.0514)$ \\
\hline & Poor or defective road surface & $1.6837(0.6150)$ & $1.7883(0.0093)^{*}$ & $1.5644(0.8391)$ \\
\hline \multirow{5}{*}{ Environmental condition } & Potholes & $0.1393(0.3409)$ & $0.3673(0.8122)$ & $0.5617(0.3823)$ \\
\hline & Rain & $1.0803(0.8470)$ & $0.7133(0.0083)^{*}$ & $0.8623(0.8684)$ \\
\hline & Slippery road & $0.5801(<0.0001)^{*}$ & $0.7383(<0.0001)^{*}$ & $0.7683(0.0012)^{*}$ \\
\hline & Stationary or parked vehicle & $0.3121(0.0012)^{*}$ & $0.1161(0.1957)$ & $0.4131(<0.0001)^{*}$ \\
\hline & 00-05 hours & Reference & & \\
\hline \multirow[t]{3}{*}{ Hour interval } & 06-13 hours & $1.5223(<0.0001)^{*}$ & $1.5757(0.3775)$ & $0.7782(0.5987)$ \\
\hline & 14-23 hours & $2.7720(0.0090)^{*}$ & $2.5924(0.2536)$ & $1.8745(0.4639)$ \\
\hline & Autumn & Reference & & \\
\hline \multirow{5}{*}{ Season } & Spring & $0.6137(0.0514)^{*}$ & $0.6509(0.0615)$ & $0.5641(0.0094)^{*}$ \\
\hline & Summer & $0.6150(0.8391)$ & $0.5985(0.3409)$ & $0.7125(0.8122)$ \\
\hline & Winter & $0.4669(0.3823)$ & $0.3731(0.8470)$ & $0.3706(0.0083)^{*}$ \\
\hline & District & Reference & & \\
\hline & National & $0.4982(0.8684)$ & $0.4421(<0.0001)^{*}$ & $0.6134(<0.0001)^{*}$ \\
\hline \multirow[t]{5}{*}{ Road type } & Others & $0.4571(0.0011)^{*}$ & $0.3405(0.0012)^{*}$ & $0.3379(0.1957)$ \\
\hline & Provincial & $2.9075(<0.0001)^{*}$ & $2.1828(<0.0001)^{*}$ & $0.2473(0.3775)$ \\
\hline & Regional & $0.8055(0.5987)$ & $0.6543(0.0090)^{*}$ & $0.8023(0.2536)$ \\
\hline & Capricorn district & Reference & & \\
\hline & Mopani district & $0.3991(0.4639)$ & $0.6121(0.0514)$ & $0.6682(0.0615)$ \\
\hline \multirow[t]{3}{*}{ Regional distribution } & Sekhukhune district & $0.0764(0.0094)^{*}$ & $0.1193(0.8391)$ & $0.1947(0.3409)$ \\
\hline & Vhembe district & $0.1598(0.8122)$ & $0.1398(0.3823)$ & $0.3247(0.8470)$ \\
\hline & Waterberg district & $0.2542(0.0083)^{*}$ & $0.3471(0.8684)$ & $0.3981(<0.0001)^{*}$ \\
\hline
\end{tabular}

${ }^{*} P$ value: significant at 0.05 ; Model 1: injury severity vs. property damage; Model 2: death and serious injury vs. property damage and minor injury; Model 3 : death vs. serious injury, minor injury, and property damage.

in previous studies in which it was observed that rain, snowy or slippery roads, and busy highways reduce the severity $[27,28,36]$.

Considering several strengths of the study, including the large sample size, limitations should be noted. The study used a secondary dataset collected and recorded by the Limpopo Provincial Department of Roads and Transport. It is noted that some important third variables were not available in the dataset, such as demographics (age, sex, race, and ethnicity), and road conditions such as road segment 
length, width, and number of ramps and bridges; therefore, when the omitted variables are significant covariates for injury severity, this might result in residual confounding. Moreover, another limitation comes from considering severe crashes from only one province.

\section{Conclusions}

The main purpose of this study was to determine the influence of environmental factors on injury severity and to identify whether their impact on injury severity levels varies. It was found in the study that the underlying assumption of the OLR model was violated to the extent that the relationship between each pair of outcome groups (property damage, minor, serious, and death) is not the same. The GOLR model seemed to be an effective predicting model that can be adapted to determine the influence of environmental factors on injury severity. The results of the present study suggest that environmental factors such as slippery road conditions, rainy weather, and spring season lower the likelihood of severe crash occurrence. On the other hand, poor or defective road surfaces, time intervals (6 a.m. to 11 p.m.), and provincial roads have a higher likelihood of severe crash occurrence. Finally, it may be concluded that frequent road maintenance on provincial roads is required.

\section{Data Availability}

The data supporting the findings of the article are available from the corresponding author upon reasonable request.

\section{Disclosure}

This paper was taken out of a master's thesis written by the author [36].

\section{Conflicts of Interest}

The authors declare that they have no conflicts of interest.

\section{Acknowledgments}

The author would like to thank the Department of Roads and Transport in Limpopo Province for permission to conduct the study. He gives thanks to his master's supervisors, Professor Abebe Tessera and Mr. Negussie Yibas.

\section{References}

[1] World Health Organization, Global Status Report on Road Safety 2015, World Health Organization, Geneva, Switzerland, 2015.

[2] World Health Organization, Global Status Report on Road Safety 2013: Supporting a Decade of Action: Summary (No. WHO. NMH. VIP 13.01), World Health Organization, Geneva, Switzerland, 2013.

[3] M. Jalilian, H. Safarpour, J. Bazyar, M. Keykaleh, L. Malekyan, and A. Khorshidi, "Environmental related risk factors to road traffic accidents in Ilam, Iran," Medical Archives, vol. 73, no. 3, p. 169, 2019.
[4] Road Traffic Management Corporation (RTMC), Road Traffic Report Calendar: 1 January - 31 December 2016, Road Traffic Management Corporation (RTMC), Gauteng, South Africa, 2016.

[5] Department of Road and Transport (Dot): 2007. Department of Road and Transport. [Online] Available at: http://www. safiri.co.za/lpfdb/roads-traffic-management.html.

[6] G. T. Harris and I. A. Olukoga, "A cost benefit analysis of an enhanced seat belt enforcement program in South Africa," Injury Prevention, vol. 11, no. 2, pp. 102-105, 2005.

[7] T. Verster and E. Fourie, "The good, the bad and the ugly of South African fatal road accidents," South African Journal of Science, vol. 114, no. 7-8, pp. 63-69, 2018.

[8] Y. Li and Y. Bai, "Comparison of characteristics between fatal and injury accidents in the highway construction zones," Safety Science, vol. 46, no. 4, pp. 646-660, 2008.

[9] H. R. Burgut, A. Bener, H. Sidahmed, R. Albuz, R. Sanya, and W. A. Khan, "Risk factors contributing to road traffic crashes in a fast-developing country: the neglected health problem," Ulusal travma ve acil cerrahi dergisi = Turkish journal of trauma \& emergency surgery: TJTES, vol. 16, no. 6, pp. 497-502, 2010.

[10] A. Morgan and F. L. Mannering, "The effects of roadsurface conditions, age, and gender on driver-injury severities," Accident Analysis \& Prevention, vol. 43, no. 5, pp. 1852-1863, 2011.

[11] L. Aarts and I. Van Schagen, "Driving speed and the risk of road crashes: a review," Accident Analysis \& Prevention, vol. 38, no. 2, pp. 215-224, 2006.

[12] X. Zhu and S. Srinivasan, "A comprehensive analysis of factors influencing the injury severity of large-truck crashes," Accident Analysis \& Prevention, vol. 43, no. 1, pp. 49-57, 2011.

[13] J. D. Lemp, K. M. Kockelman, and A. Unnikrishnan, “Analysis of large truck crash severity using heteroskedastic ordered probit models," Accident Analysis \& Prevention, vol. 43, no. 1, pp. 370-380, 2011.

[14] L. Vogel and C. J. Bester: A Relationship between Accident Types and Causes. SATC 2005.

[15] S. Jung, X. Qin, and D. A. Noyce, "Rainfall effect on singlevehicle crash severities using polychotomous response models," Accident Analysis \& Prevention, vol. 42, no. 1, pp. 213-224, 2010.

[16] V. Cantillo, P. Garcés, and L. Márquez, "Factors influencing the occurrence of traffic accidents in urban roads: a combined GIS-Empirical Bayesian approach,” Dyna, vol. 83, no. 195, pp. 21-28, 2016.

[17] P. C. Anastasopoulos and F. L. Mannering, "A note on modeling vehicle accident frequencies with random-parameters count models," Accident Analysis \& Prevention, vol. 41, no. 1, pp. 153-159, 2009.

[18] A. Ishtiaque and S. Ullah, "The influence of factors of migration on the migration status of rural-urban migrants in Dhaka, Bangladesh," HUMAN GEOGRAPHIES-Journal of Studies and Research in Human Geography, vol. 7, no. 2, pp. 45-52, 2013.

[19] R. O. Mujalli, G. López, and L. Garach, "Modeling injury severity of vehicular traffic crashes," in Proceedings of the 2017 International Conference on Automation, Control and Robots, pp. 51-55, Prague, Czech Republic, June 2017.

[20] Q. Wu, G. Zhang, Y. Ci, L. Wu, R. A. Tarefder, and A. D. Alcántara, "Exploratory multinomial logit model-based driver injury severity analyses for teenage and adult drivers in intersection-related crashes," Traffic Injury Prevention, vol. 17, no. 4, pp. 413-422, 2016. 
[21] C. Ma, J. Zhou, and D. Yang, "Causation analysis of hazardous material road transportation accidents based on the ordered logit regression model," International Journal of Environmental Research and Public Health, vol. 17, no. 4 , p. $1259,2020$.

[22] R. Williams, "June. Ordinal regression models: problems, solutions, and problems with the solutions," in German State User Group MeetingsIndianapolis, IND, USA, 2008.

[23] R. Brant, "Assessing proportionality in the proportional odds model for ordinal logistic regression," Biometrics, vol. 46, pp. 1171-1178, 1990.

[24] F. Malin, I. Norros, and S. Innamaa, "Accident risk of road and weather conditions on different road types," Accident Analysis \& Prevention, vol. 122, pp. 181-188, 2019.

[25] S. H. Harith, N. Mahmud, and M. Doulatabadi, "Environmental factor and road accident: a review paper," in Proceedings of the International Conference on Industrial Engineering and Operations Management, pp. 3409-3418, Rio de Janeiro, Brazil, July 2019.

[26] S. Saha, P. Schramm, A. Nolan, and J. Hess, "Adverse weather conditions and fatal motor vehicle crashes in the United States, 1994-2012," Environmental Health: A Global Access Science Source, vol. 15, no. 1, pp. 104-109, 2016.

[27] X. Jiang, B. Huang, R. L. Zaretzki, S. Richards, X. Yan, and $\mathrm{H}$. Zhang, "Investigating the influence of curbs on singlevehicle crash injury severity utilizing zero-inflated ordered probit models," Accident Analysis \& Prevention, vol. 57, pp. 55-66, 2013.

[28] A. Theofilatos and G. Yannis, "A review of the effect of traffic and weather characteristics on road safety," Accident Analysis \& Prevention, vol. 72, pp. 244-256, 2014.

[29] D. Akin, V. P. Sisiopiku, and A. Skabardonis, "Impacts of weather on traffic flow characteristics of urban freeways in Istanbul," Procedia-Social and Behavioral Sciences, vol. 16, pp. 89-99, 2011.

[30] Y. Li, C. Liu, and L. Ding, "Impact of pavement conditions on crash severity," Accident Analysis \& Prevention, vol. 59, pp. 399-406, 2013.

[31] J. Lee, B. Nam, and M. Abdel-Aty, "Effects of pavement surface conditions on traffic crash severity," Journal of Transportation Engineering, vol. 141, no. 10, p. 04015020, 2015.

[32] Y. Meng, "Estimation of crash severity on mountainous freeways in Chongqing," Mathematical Problems in Engineering, vol. 2017, Article ID 9764309, 8 pages, 2017.

[33] X. Yan, B. Wang, M. An, and C. Zhang, "Distinguishing between rural and urban road segment traffic safety based on zero-inflated negative binomial regression models," Discrete Dynamics in Nature and Society, vol. 2012, Article ID 789140, 11 pages, 2012.

[34] C. Cabrera-Arnau, R. Prieto Curiel, and S. R. Bishop, "Uncovering the behaviour of road accidents in urban areas," Royal Society Open Science, vol. 7, no. 4, p. 191739, 2020.

[35] K. Sangkharat, J. E. Thornes, P. Wachiradilok, and F. D. Pope, "Determination of the impact of rainfall on road accidents in Thailand," Heliyon, vol. 7, no. 2, p. e06061, 2021.

[36] M. Mphekgwana, A. Tessera, and N. Yibas: Ulspace.ul.ac.za. 2022: http://ulspace.ul.ac.za/bitstream/handle/10386/3483/mphegwana mp_2020.pdf?isAllowed $=$ y\&sequence $=1>$. 